\title{
Falls - the socio-economic and medical aspects important for developing prevention and treatment strategies
}

\author{
Marcin Mikos ${ }^{1, A, D, F} \oplus$, Angelica Trybulska ${ }^{2, D, F} \oplus$, Aleksandra Czerw ${ }^{3, A-B} \oplus$ \\ ${ }^{1}$ Department of Emergency Medical Services, Faculty of Medicine and Health Sciences, Andrzej Frycz Modrzewski \\ University, Kraków, Poland \\ ${ }^{2}$ Faculty of Medicine, Jagiellonian University Medical College, Kraków, Poland \\ ${ }^{3}$ Department of Health Economics and Medical Law, Medical University, Warsaw, Poland \\ A - Research concept and design, B - Collection and/or assembly of data, C - Data analysis and interpretation, \\ $D$ - Writing the article, E - Critical revision of the article, F - Final approval of article
}

Mikos M, Trybulska A, Czerw A. Falls - the socio-economic and medical aspects important for developing prevention and treatment strategies. Ann Agric Environ Med. 2021; 28(3): 391-396. doi: 10.26444/aaem/122409

\begin{abstract}
Introduction. Although falls occur extremely frequently, they are still one of the least investigated causes of death. According to the World Health Organization, around 37.3 million falls occur globally every year resulting in the deaths of over 660,000 adults and almost 30,000 children.

Objective. The aim of this review is to evaluate the most up-to-date and comprehensive knowledge on falls and their consequences, especially in populations at the highest risk of fatal falls.

Brief description of state of knowledge. Currently, there is a limited amount of literature which analyzes falls. Falls affect all age groups, but their location, cause, and severity vary among different populations. Individuals who are particularly at risk of falling at home include younger children and the elderly. Research indicates that falls are one of the main causes of work-related injuries and deaths, especially those occurring at significant heights. Falls in the home environment are the second most common cause of death in over $33 \%$ of accidents and the main cause of injury in $41.2 \%$ of accidents. During patient hospitalizations, falls generate additional burdens and costs on the healthcare system.

Conclusions. This review elaborated on the nature of falls in different populations and analyzed the influence falls have on the healthcare system, in society, and on the economy. This knowledge is particularly important in an aging society, which will inevitably face increasing problems due to falls in the near future. As the emphasis on falls increases, leaders and lawmakers will be pushed to establish individualized prevention measures, as described in this review, for specific risk groups to effectively prevent falls and their consequences.
\end{abstract}

\section{Key words}

falls, patient safety, healthcare system, accident prevention, Elderly population

\section{INTRODUCTION AND OBJECTIVE}

A fall is an event which results in a person coming to rest inadvertently on the ground or floor or other lower level [1]. According to the World Health Organization (WHO), around 37.3 million falls occur globally every year resulting in the deaths of over 660,000 adults and almost 30,000 children under the age of five [2]. Falls are still one of the least investigated and one of the most complex causes of death; therefore, their incidence requires more detailed analysis and in-depth scientific research [3]. Understanding the trends associated with fall mortality in different environments, circumstances, and populations allows for both a better understanding of these issues, and for the possibility of developing appropriate prevention programmes for specific target groups while simultaneously reducing the risk of death [4]. To gain a better insight into the problem of falls from a public health standpoint, it is important to take into account the economic and social consequences of falls, such as the

Address for correspondence: Marcin Mikos, Department of Emergency Medical Services, Faculty of Medicine and Health Sciences, the Andrzej Frycz Modrzewski Kraków University, Poland

E-mail: mikos@ziz.com.pl

Received: 18.03.2020; accepted: 14.05.2020; first published: 28.05 .2020 cumulative costs of medical services, sick leave, and acquired disability.

In this review, the issue of death as a result of a fall particularly concerns three groups: children in their developmental stages, employees exposed to accidents in the work environment, and seniors vulnerable to falls in the home environment, residential homes, and medical facilities. The main cause of injuries and deaths of those under the age of 60 is predominated by falls from a significant height (building or other tall structures). In contrast, the dominant reason for falls in people over the age of 60 are those occurring at ground level due to slipping, tripping, and stumbling. The average mortality of falls is $10 \%$ and more than half of these deaths are a result of head injuries [5]. In children, especially those under 5 years of age, the highest risk of falling and its associated lethal consequences occur in the home [6, 7] as well as during hospitalization [8]. Among employed individuals, the issue of falls, and consequently death, affects virtually all sectors of the economy, particularly in the construction sector. One of the main causes of fatal accidents in the workplace are falls from a significant height during construction work. These types of falls account for the majority of fatal accidents annually worldwide $(60,000)$ [9]. The risk of death increases concomitantly with age and 
reaches its highest point after an employee reaches the age of 50 , especially in men [10]. However, $70 \%$ of all deaths from falls in all age groups occur in the elderly population $(>60$ years of age). Globally, it is estimated that around 457,000 people die annually due to injuries caused by falls [11].

\section{OBJECTIVE}

The aim of this review is to evaluate the most up-to-date and comprehensive knowledge about falls and their consequences, especially in populations at the highest risk of fatal falls. The review also describes falls in different aspects of life. The summary of knowledge to-date in these areas will allow for individualized prevention measures to be taken for specific risk groups to effectively prevent falls and their consequences, including death. This knowledge is useful for various types of leaders and lawmakers who may take action in improving fall prevention in order to improve public health.

\section{MATERIALS AND METHOD}

In February 2020, an extensive manual search was made through the major electronic databases (PubMed, EMBASE, Web of Science, and Google Scholar) in order to identify relevant studies published on falls and their socio-economic background. No lower date limit was set. The articles were limited to those published in English and Polish. The following search terms were used: "falls", "economy", "economic", "elderly", "prevention", "socio-economic" and "social factors" in different combinations in accordance with the Boolean logic rules. The articles were analyzed first based on the title, then by the abstract, and finally by their full text. The studies ultimately selected for inclusion in this study were limited to only full-text original and full-text review articles that explored the relevant subject. Based on the authors' clinical and research expertise, all the selected articles were the most pertinent available for this review.

\section{DESCRIPTION AND THE STATE OF KNOWLEDGE}

Falls at work. Socias-Morales et al. 2018 [12] indicate that falls are one of the main causes of work-related injuries and deaths. In 2014, there were 30,000 injuries in the United States as a consequence of falling at work, making falls the second most frequent cause of death among employees. The largest number of injuries and deaths occured when employees fell from a significant height. In about $50 \%$ of cases, this height was approximately four meters. Occupations that require employees to work on both fragile and slippery surfaces or working platforms at great heights (i.e. ladders, scaffolding, or roofs) pose the greatest occupational risk to employees [13].

In most cases, falling is a result of failing to properly follow safety and security measures in the workplace. Based on American observations and studies by Lilley et al. 2018 [14], the groups at greatest risk of falling in the workplace include men working in construction and employees between the ages of 45-54 and 55-64. Intracranial injury is usually the main injury leading to death after a fall $[15,16]$. Observations by Konda S. et al. 2016 [16] revealed that injuries to the skull accounted for $42 \%$ of all fall-related fatalities in the construction sector. According to Socias-Morales et al. 2018 [12], fatal falls are more common in small businesses with 10 or fewer employees.

In Poland, falls (including slips and trips) accounted for almost $30 \%$ of all work-related accidents. Of a total of 24,122 falls in the workplace, 5,379 occurred from a significant height and 18,743 occurred at ground level [17]. These types of work accidents occur mainly in such occupations as manufacturing (5,286 incidents), healthcare (2,898 incidents), motor vehicle repair (2,603 incidents), and construction (1,576 incidents). A total of 49 fatal falls occurred in 2017 with a majority in construction (18 deaths) and manufacturing (12 deaths).

In Poland, register of agricultural falls is kept separately. According to data from 2017, there were 6,653 falls in the agricultural industry which included 12 deaths [18]. The largest number of falls in agriculture was recorded in the Lubelskie (1,045 falls) and Mazowieckie (899 falls) provinces [18]. In comparison to 2016 (16 deaths), 2017 (12 deaths) saw a decrease in the number of deaths due to falls in agriculture [18], which are also a primary cause of deteriorating health. According to research by Gross N. et al. 2015 [19], falls accounted for $20 \%$ of all analyzed events directly related to the performance of work in agriculture. Falls, most often from a significant height, were one of the main causes of death in a retrospective analysis by Rorat M. et al. 2015 [20] for the Lower Silesia region in Poland.

Falls in the home environment. In the United States between 2000-2008, home accidents accounted for over 32,000 deaths. Moreover, falls at home are the second most common cause of death in over $33 \%$ of accidents and the main cause of injury in $41.2 \%$ of accidents [21]. Individuals who are particularly at risk of falling at home include younger children and the elderly.

About $80 \%$ of all falls recorded in children ages four years and younger occur at home, but in children ages 5-14, this percentage drops to $50 \%$. Overall, falls that occur at home account for $8 \%$ of all fatalities in children worldwide [22]. Gielen A. et al. (2015) [21] suggests that factors such as the child's age, size, and stage of development play an important role in determining the probability of falling. In the younger group, up to four years of age, a greater number of injuries were observed (39\% of all falls) in children who fell [23]. The largest number of falls in the home environment occur from a balcony, stairs, and furniture, respectively [24]. Babies are particularly at a higher risk of falling from furniture or stairs. This increased risk can, in part, be attributed to baby walkers. Older children more commonly fall from windows. According to American data, out of approximately 3,000 children who fall out of a window per year, $34 \%$ required hospitalization [25].

The elderly are the group at the highest risk of injury in accidental falls at home. In addition, the risk of death as a result of a fall increases concomitantly with age. Many factors contribute to the risk of older individuals falling at home, including the use of drugs causing dizziness, or physiological impairment of vision, as well as the absence of age-friendly home environment adaptations (e.g. lack of handles in bathrooms, slippery surfaces, or carpeted floors). The accumulating effect of these risk factors contributes to the increased likelihood of an elderly person falling [26]. According to the Centres for Disease Control and Prevention (CDC), an estimated 2.3 million elderly individuals are hospitalized globally every year because of falls [27]. 
Falls of the elderly. Age is a major risk factor for falling. Elderly people over 60 years of age are particularly vulnerable to falls. It is estimated that every year one-third of individuals above the age of 65 who live alone, experience a fall [28]. In addition to increased age, the issues of reduced physical activity, the presence of chronic conditions (e.g. arthritis, neurological diseases, etc.), age-related changes in gait and balance, and the potential side-effects of medications affecting the central nervous system, can all propagate falls in the elderly. In a Polish study involving patients with rheumatoid arthritis (RA), $43 \%$ of participants had experienced a fall (or multiple falls) during a period of 12 months [29]. This confirmed that falls are a frequent and serious complication in patients with RA. The main factors contributing to falls in RA patients are foot deformities, antihypertensive medications, dizziness, and a high score on the Health Assessment Questionnaire (HAQ) [29]. Additionally, Khow K. et al. (2017) [28] indicate impaired vision and hearing loss as main risk factors for falling in the elderly.

The elderly in nursing homes also commonly suffer from a spectrum of chronic conditions that put them at risk of falling. In the study by Michalik C. et al. (2013) [30], heart failure (HF) was observed in more than $25 \%$ of nursing home patients with advanced age. Moreover, patients with HF suffered from an increased number of comorbidities and required multidrug therapies [30], which may be the source of serious complications and affect patient safety where falling is concerned. Furthermore, dementia is more frequently observed in individuals living in nursing homes, and the elderly with dementia may have reduced physical fitness compared to those without dementia [31]. Cognitive impairment, like dementia, may lead to poor motor coordination and difficulty in performing daily activities, which further increase the risk of falling. Matusik P. el al. (2012) [32] describes how frailty and cognitive impairment are both frequently present in patients in nursing homes, and together increase the risk of falls, disability, hospitalization, and death.

As a consequence, after a fall, older people can develop a fear of falling. Such anxiety can occur in $20-40 \%$ of elderly people and contributes to the weakening of physical health and a decrease in the ability to function normally. This can lead to depression, social isolation, and eventually institutionalization [28].

Accidents, the a majority being falls, are the seventh cause of death in the United States in this age group (over 65) [33]. The mortality rate in 2017 was 46.29 per 100,000 [34], with the he death rate being the highest in the older age groups (over 85), and among men. According to Burns E. et al. (2018), the death rates were 257.9 per 100,000 for people aged over 85 and 72.3 per 100,000 for men, [35]. It is estimated that worldwide every third person over the age of 65 is at risk of falling at least once a year [36]. Taking into account the fact that society is aging, the problem of falls is predicted to increase.

Falls in the healthcare system. Falls in the healthcare system are a unique category of injuries because these events can affect two groups: patients, and to a lesser extent, medical staff. According to estimates in the United States, there are between 700,000 and 1 million patient falls that occur in hospitals every year. Of those patients affected, about 30$35 \%$ are injured and their injuries can result in a prolonged hospital stay of an additional six days [37]. The main risk factors for patient falls include insufficient assessment of the risks of falling by medical personnel, lack of communication between medical staff, independent attempts to use the toilet by patients at risk of falling, problems with patients seeking assistance, lack of patient and family education about falls, and finally, consumption of medications that may disturb balance [37]. Research by Morris R. et al. (2017) [38] based on data from patient safety monitoring, indicates that hospital falls are the most frequently reported incidents $(250,000$ events) in England and Wales. Of these reported falls, 30$50 \%$ resulted in physical injury. Bone fractures occurred in $1-3 \%$ of these cases.

Falls in public healthcare facilities generate both direct and indirect costs for the healthcare system. This mainly applies to falls that result in non-fatal injury because such accidents require longer treatment, and prolong the time to return to work. In addition, falling can lead to a deterioration in health and, as a consequence, can be a future cause of death. Based on a study carried out in the geriatric ward of a Polish hospital, patients who suffered injuries after a fall where hospitalized for an average of 24 days, which is four times longer than the average hospitalization time for all patients [39]. Such extended hospitalizations and deaths occurring during hospitalization generate additional costs. According to estimates from other countries, the consequences of falls absorb one-third of the costs associated with all injuries and are the leading cause of death from injuries in the elderly [40]. With the limited financial capabilities of public facilities and the high costs of hospital treatment, both fatal and non-lifethreatening falls generate an additional burden on the health care system. In Poland, there are no studies on the costs of falls in healthcare facilities. This subject requires further analysis after taking into account the public expenditure and the growing elderly population, the age group which ultimately suffers the greatest risk of health consequences after a fall.

The importance of informal care. Informal care is that which is provided primarily by family members, distant relatives, friends, and neighbours to those who have experienced a fall. Individuals who provide such informal care do not officially receive any remuneration [41]. In Poland, due to the limited amount of research on informal care and its role in falls, formulating any estimations is very difficult. According to the European Health Interview Survey (EHIS), the Central Statistical Office states that in 2014 every sixth adult in Poland provided informal care. In three-quarters of cases, the persons providing care were family members [42]. In literature worldwide, research on the topic of informal care for those who experience a fall is mainly focused around the elderly. A fall in the elderly population produces greater health consequences and is associated with longer recovery times. The main role of an informal care provider is to be a source of emotional support and to assist in basic daily activities (eating and toilet hygiene) and instrumental daily activities (shopping and cooking) [43]. The impact of informal care on the phenomenon of falls is based on the "Person-environment fit" (P-E fit) theory and the assumption that a care provider can have an affect on the risk of falling of an exposed person in two ways. First, the care provider can reduce the influence of any external factors, e.g. by modifying the home environment of the individual being cared for, and secondly, by assisting with activities that involve a greater 
risk of falling (bathing and getting around) [44]. According to the results of a study by Hoffman G. et al. (2017) [44], there is a decrease in the number of falls that occur with daily activities of the elderly when there is more support and investment from an informal care provider.

It is important to acknowledge that the time and devotion required from a caretaker can limit the caretaker's professional career and burden them financially. This absence of labor can, in turn, generate additional costs for the economy. Joo H. et al. 2017 [45] investigated the economic burden that resulted from the informal care of the elderly after a stroke or fall. According to the study, an average of 3 hours a week is devoted to the informal care of a person after a fall. The length of care increases to 10 hours a week when there is an additional influential factor such as a stroke. As a result, the informal care of a person with a traumatic injury after a fall generates an annual economic burden on the economy of about 6 billion dollars (USD).

Fall prevention. Fall prevention should include two complementary areas focused on both broad-based and individual improvements. The first area should consist of systemic actions aimed at improving the safety of the groups at risk of falling. This mainly concerns the prevention of falls in the work environment by creating, implementing, and enforcing compliance with health and safety regulations (e.g. use of safety nets or non-slip shoes) [46].

Another example of a solution at the systemic level is the implementation of a fall preventative strategy for the health care system. Stopping Elderly Accidents, Deaths \& Injuries (STEADI) is a programme developed by the Centres for Disease Control and Prevention (CDC) that provides tools (i.e. algorithm, pocket guides) and resources to educate and train health care providers, as well as materials for patients and family caregivers on fall preventions [47]. This is a systemic solution addressed to healthcare workers, mainly to medical teams at the level of primary health care. The main objectives of the STEADI programme are to screen patients for risk of falling, asses modifiable risk factors, and intervene to reduce risk of falling by using effective clinical and community strategies [47]. The initial steps recommended to assess patient risk of falling include: 1) checking patient medication interactions that may lead to an increased risk of falling, 2) conducting periodic interviews to asses any balance disorders and previous falls, and 3) Vitamin D supplements to improve the function of muscle, bone, and nervous system [48]. The STEADI programme encourages a multidisciplinary approach by bringing together all healthcare workers to improve the safety of the elderly population. Such initial steps could be assisted by the collaboration of pharmacists, with their expertise on medications and their side-effects, and primary care providers to optimize patient care [48]. A study conducted in Upstate New York revealed that the elderly, after the implementation of a STEADI fall plan, experienced fewer fall-related hospitalizations and, overall, their odds of hospitalization were $40 \%$ lower than the elderly without a fall prevention plan $(\mathrm{p}<.05)$ [49]. Another example of an evidence-based guideline for fall prevention is a 10-step-protocol that can be applied regardless of the place of residence of an older individual (i.e. community, assisted living facility). This stepwise approach can provide tools for screening falls, assessing fall risk, evaluating and determining abnormal gait or balance, and conducting a comprehensive fall assessment that will help determine whether additional interventions are needed. Additionally, it may help establish an individualized multifactorial fall intervention programme based on individual risk factors, needs, and living conditions [50].

The second area of fall prevention should include individual measures that can help prevent the risk of falling (i.e. adjusting the home environment). The most effective way to prevent falls at home is through structural home modifications (e.g. eliminating steps, covering the floor with non-slip material, installing handrails on stairs, and enclosed balconies) [51, 52]. According to a study in New Zealand by Keall M. et al. (2015) [53], the average cost of securing a home to prevent falls is around 830 dollars (USD). It is important to note that such home modifications are permanent and are long-term preventative measures. Such modifications can also be extended to hospitals and care facilities by installing safe flooring to reduce the incidence of fall-related injuries. In a study by Hanger C. et al. (2017) [54], fall-related injuries are significantly less frequent and the severity of injury was reduced when it occurred on low-impact flooring (LIF), which reduced injury by $35 \%$. Modification of the living or residential environment of the elderly can be a crucial for preventing falls and reducing their severity when they occur.

Another example of individual preventative measures is ensuring adequate physical activity. Carande-Kulis V. et al. (2015) [55] carried out a cost-effect analysis of three local programmes aimed at improving the physical activity of senior citizens. One of the analyzed programsme, "Tai Chi: Moving for Better Balance”, reduced the participants' probability of falling by $55 \%$. The return on investment was estimated to be $509 \%$ for every dollar invested in the programme. The greatest success in interventional exercise programmes can be observed in the elderly, but the effects were only evident after 50 hours of training [56]. In the Vlaeyen E. et al. (2015) [57] meta-analysis of the effectiveness of preventive measures for falls in nursing homes, the majority of fall prevention programmes were aimed at older individuals in the home environment, or in social care facilities. Additionally, the community, informal care givers, and general practitioners played an important role in engaging elderly individuals in exercise programmes. In a study evaluating the implementation of a home-based exercise programme for older adults, an important contributing factor that helped stimulate participation in the programme was dialogue between the health care professionals and the older adults. The dialogue emphasized the negative consequences of a fall, as well as the positive effects of preventing a fall (i.e. maintain functional independence) [58].

Moreover, as technology advances, new innovative exercise methods for fall prevention emerge to help older adults to stay interested, motivated, and to adhere to an exercise routine. Smart phone and tablet applications are available for delivering balance training and provide a broad range of enjoyable exercise options while encouraging participation through immediate performance feedback [59]. Arkkukangas M. at el. (2020) [60] explored the experiences of older adults by using a mobile application for fall prevention exercises. The participants stated that they liked being responsible for their own exercises and the application gave them a sense of awareness for managing their daily lives The application additionally motivated the participant to set goals and to adhere to them, and allowed the monitoring 
of exercises and evaluation of individual progress [60]. The useof technological devices for a home-based programme is suggested to be sustainable, effective, and cost-effective [61].

It is important to remember that although individual preventive programmes are effective, the best preventive action can be obtained by combining several types of interventions: 1) ensuring supervision over the general state of health, and modifying physiological risk factors by healthcare professionals, 2) structural solutions in the home environment and undertaking physical activity, and 3) education of people exposed to falls [62]. Vieira E. et al. (2016) [62], however, emphasize that the implementation of such solutions requires good coordination and considerable effort on the part of the healthcare system and local authorities.

\section{CONCLUSIONS}

In conclusion, this review elaborated on the nature of falls in different populations and analyzed the influence falls have on the healthcare system, on society, and on the economy. This knowledge is particularly important in an aging society which, in the near future, will inevitably face increasing problems due to falls. The authors acknowledge the limitations of the currently available literature on falls and believe that further well-designed studies are necessary. It is especially crucial to address the unresolved problems that falls present, and to assist in the development of new strategies in fall prevention and treatment leading to the improvement of the quality of life of the elderly and others at risk from falls.

\section{REFERENCES}

1. World Health Organization. Falls [Internet]. 2018 [cited 2020 Mar 4]. Available from: https://www.who.int/news-room/fact-sheets/detail/ falls

2. World Health Organization. Global Health Estimates 2016: Deaths by Cause, Age, Sex, by Country and by Region, 2000-2016 [Internet]. Geneva; 2018. Available from: https://www.who.int/healthinfo/global burden disease/estimates/en/

3. Quigley P, Bulat T, Kurtzman E, Olney R, Powell-Cope G, Rubenstein L. Fall prevention and injury protection for nursing home residents. J Am Med Dir Assoc. 2010; 11(4): 284-93. Available from: https://doi. org/10.1016/j.jamda.2009.09.009

4. Padrón-Monedero A, Damián J, Pilar Martin M, Fernández-Cuenca R. Mortality trends for accidental falls in older people in Spain, 2000-2015. BMC Geriatr. 2017; 17(1): 276. Available from: https://doi.org/10.1186/ s12877-017-0670-6

5. Jagnoor J, Keay L, Ganguli A, Dandona R, Thakur JS, Boufous S, et al. Fall related injuries: A retrospective medical review study in North India. Injury. 2012; 43(12): 1996-2000. Available from: https://doi. org/10.1016/j.injury.2011.08.004

6. Brito M de A, Melo AMN, Veras I de C, Oliveira CMS de, Bezerra MAR, Rocha SS da. Risk factors in the domestic environment for falls in children under five years of age. Rev Gauch Enferm. 2017; 38(3): e2017-1. Available from: https://doi.org/10.1590/1983-1447.2017.03.2017-0001

7. Haarbauer-Krupa J, Haileyesus T, Gilchrist J, Mack KA, Law CS, Joseph A. Fall-related traumatic brain injury in children ages $0-4$ years. J Safety Res. 2019; 70: 127-33. Available from: https://doi.org/10.1016/j. jsr.2019.06.003

8. AlSowailmi BA, AlAkeely MH, AlJutaily HI, Alhasoon MA, Omair A, AlKhalaf HA. Prevalence of fall injuries and risk factors for fall among hospitalized children in a specialized children's hospital in Saudi Arabia. Ann Saudi Med. 2018; 38(3): 225-9. Available from: https://doi. org/10.5144/0256-4947.2018.225
9. Chen H, Luo X. Severity Prediction Models of Falling Risk for Workers at Height. Procedia Eng. 2016; 164: 439-45. Available from: https://doi. org/10.1016/j.proeng.2016.11.642

10. Yi KH. The High-risk Groups According to the Trends and Characteristics of Fatal Occupational Injuries in Korean Workers Aged 50 Years and Above. Saf Health Work [Internet]. 2018; 9(2): 184-91. Available from: https://doi.org/10.1016/j.shaw.2018.01.005

11. Council NS. Injury Facts 2017. 17th ed. National Safety Council; 2017 [cited 2020 Mar 2]. Available from: https://injuryfacts.nsc.org/

12. Socias-Morales CM, Chaumont Menéndez CK, Marsh SM. Fatal workrelated falls in the United States, 2003-2014. Am J Ind Med. 2018; 61(3) 204-15. Available from: https://doi.org/10.1002/ajim.22810

13. Perotti S, Russo MC. Work-related fatal injuries in Brescia County (Northern Italy), 1982 to 2015: A forensic analysis. J Forensic Leg Med. 2018 Aug; 58: 122-5. Available from: https://doi.org/10.1016/j. jflm.2018.06.002

14. Lilley R, Jaye C, Davie G, Keeling S, Waters D, Egan R. Age-related patterns in work-related injury claims from older New Zealanders, 2009-2013: Implications of injury for an aging workforce. Accid Anal Prev. 2018; 110: 86-92. Available from: https://doi.org/10.1016/j. aap.2017.10.022

15. U.S. Bureau of Labor Statistics. Census of Fatal Occupational Injuries (CFOI) - Current and Revised Data [Internet]. [cited 2020 Mar 10]. Available from: https://www.bls.gov/iif/oshcfoil.htm\#2017

16. Konda S, Tiesman HM, Reichard AA. Fatal traumatic brain injuries in the construction industry, 2003-2010. Am J Ind Med. 2016; 59(3): 212-20. Available from: https://doi.org/10.1002/ajim.22557

17. Główny Urząd Statystyczny. Accidents at work in 2017 [Internet]. 2018. Available from: https://stat.gov.pl/obszary-tematyczne/rynek-pracy/ warunki-pracy-wypadki-przy-pracy/wypadki-przy-pracy-w-2017roku,4,11.html

18. Główny Urząd Statystyczny. Accidents at work on private farms in agriculturea by contact-modes of injury and by voivodships. Accidents at work in 2017. 2018.

19. Gross N, Young T, Ramirez M, Leinenkugel K, Peek-Asa C. Characteristics of Work- and Non-work-Related Farm Injuries. J Rural Health. 2015; 31(4): 401-9. Available from: https://doi.org/10.1111/ jrh.12121

20. Rorat M, Thannhauser A, Jurek T. Analysis of injuries and causes of death in fatal farm-related incidents in Lower Silesia, Poland. Ann Agric Environ Med. 2015; 22(2): 271-4. Available from: https://doi. org/10.5604/12321966.1152079

21. Gielen AC, McDonald EM, Shields W. Unintentional home injuries across the life span: problems and solutions. Annu Rev Public Health. 2015; 36(1): 231-53. Available from: https://doi.org/10.1146/annurevpublhealth-031914-122722

22. Gill AC, Kelly NR. Prevention of falls in children - UpToDate [Internet]. UpToDate.inc. 2019 [cited 2020 Feb 29]. Available from: https://www. uptodate.com/contents/prevention-of-falls-in-children

23. Centers for Disease Control and Prevention. A National Action Plan for Child Injury Prevention: Reducing Fall-Related Injuries in Children [Internet]. 2013 [cited 2020 Feb 29]. Available from: https://www.cdc. gov/safechild/NAP/

24. Turgut K, Sarihan ME, Colak C, Güven T, Gür A, Gürbüz S. Falls from height: A retrospective analysis. World J Emerg Med. 2018; 9(1): 46 Available from: https://doi.org/10.5847/wjem.j.1920-8642.2018.01.007

25. US Consumer Product Safety Commission. CPSC: Parents, Caregivers Should Consider Safety Before Opening Windows | CPSC.gov [Internet]. 2011 [cited 2020 Feb 29]. Available from: https://www.cpsc. gov/content/cpsc-parents-caregivers-should-consider-safety-beforeopening-windows

26. Powell-Cope G, Thomason S, Bulat T, Pippins KM, Young HM. Preventing Falls and Fall-Related Injuries at Home. AJN, Am J Nurs. 2018; 118(1): 58-61. Available from: https://doi.org/10.1097/01. NAJ.0000529720.67793.60

27. CDC. Injury prevention and control: data \& statistics (WISQARS) [Internet]. [cited 2020 Mar 10]. Available from: https://www.cdc.gov/ injury/wisqars/index.html

28. Khow KSF, Visvanathan R. Falls in the Aging Population. Clin Geriatr Med. 2017; 33(3): 357-68. Available from: https://doi.org/10.1016/j. cger.2017.03.002

29. Tomaszewski K, Chmielowska K, Zarychta M, Głuszko P. Risk factors for falls and bone fractures in patients with rheumatoid arthritis. Reumatologia/Rheumatology. 2010; 48(2): 98-103. Available from: https://www.termedia.pl/Risk-factors-for-falls-and-bone-fracturesin-patients-with-rheumatoid-arthritis, 18,14792,1,1.html 
30. Michalik C, Matusik P, Nowak J, Chmielowska K, Tomaszewski KA, Parnicka A, et al. Heart failure, comorbidities, and polypharmacy among elderly nursing home residents. Polish Arch Intern Med. 2013; 123(4): 170-5. Available from: https://dx.doi.org/10.20452/pamw.1682

31. Tomaszewski K, Matusik P, Chmielowska K, Nowak J, Parnicka A, Dubiel M, et al. Dementia and physical function among elderly residents of chosen care homes. Gerontol Pol. 2010; 18(2): 71-5. Available from: www.gp.viamedica.pl

32. Matusik P, Tomaszewski K, Chmielowska K, Nowak J, Nowak W, Parnicka A, et al. Severe frailty and cognitive impairment are related to higher mortality in 12-month follow-up of nursing home residents. Arch Gerontol Geriatr. 2012; 55(1): 22-4. Available from: https://doi. org/10.1016/j.archger.2011.06.034

33. National Center for Health Statistics. Health, United States, 2016: With chartbook on long-term trends in health [Internet]. Department of Health and Human Services. Hyattsville; 2017. Available from: https:// www.ncbi.nlm.nih.gov/pubmed/28910066

34. CDC. WISQARS Fatal Injury Reports, National, Regional and State, 1981-2017. [Internet]. [cited 2020 Mar 10]. Available from: https:// webappa.cdc.gov/sasweb/ncipc/mortrate.html

35. Burns E, Kakara R. Deaths from Falls Among Persons Aged $\geq 65$ Years United States, 2007-2016. MMWR Morb Mortal Wkly Rep. 2018; 67(18): 509-14. Available from: http://dx.doi.org/10.15585/mmwr.mm6718a1

36. Edbom-Kolarz A, Marcinkowski JT. Falls of elderly people - causes, consequences, prevention. Hygeia Public Health. 2011; 46(3): 313-8. Available from: http://www.h-ph.pl/hyg.php

37. Health Research \& Educational Trust. Preventing Patient Falls: A Systematic Approach from the Joint Commission Center for Transforming Healthcare Project. Heal Res Educ Trust. 2016; 1-20. Available from: https://www.aha.org/ahahret-guides/2016-10-04preventing-patient-falls

38. Morris R, O'Riordan S. Prevention of falls in hospital. Clin Med J R Coll Physicians London. 2017; 17(4): 360-2. Available from: https://doi. org/10.7861/clinmedicine.17-4-360

39. Dzieża-Grudnik A, Czekaj D, Wójcik-Bugajska M, Grodzicki T. [Falls during hospitalization--prevalence and consequences]. Przegl Lek. 2014; 71(10): 537-40. Available from: http://www.ncbi.nlm.nih.gov/ pubmed/25826977

40. Kujawsko-Pomorskiego UMW. Program zapobiegania upadkom dla seniorów w województwie kujawsko-pomorskim [Internet]. 2018 [cited 2020 Feb 29]. Available from: https://www.kujawsko-pomorskie.pl/ pliki/2018/zdrowie/20180607_konkurs/program.pdf

41. Broese van Groenou MI, De Boer A. Providing informal care in a changing society. Eur J Ageing. 2016; 13(3): 271-9. Available from: https://doi.org/10.1007/s10433-016-0370-7

42. Główny Urząd Statystyczny. Zdrowie i zachowanie zdrowotne mieszkańców Polski w świetle Europejskiego Ankietowego Badania Zdrowia (EHIS) 2014 r. [Internet]. Główny Urząd Statystyczny, Notatka informacyjna. Warszawa; 2015. Available from: https://stat.gov.pl/files/ gfx/portalinformacyjny/pl/defaultaktualnosci/5513/10/1/1/zdrowie_i_ zachowania_zdrowotne_mieszkancow_polski_w_swietle_badania_ ehis_2014.pdf

43. Cheung J, Hocking P. Caring as worrying: The experience of spousal carers. J Adv Nurs. 2004; 47(5): 475-82. Available from: https://doi. org/10.1111/j.1365-2648.2004.03126.x

44. Hoffman GJ, Hays RD, Wallace SP, Shapiro MF, Yakusheva O, Ettner SL. Receipt of caregiving and fall risk in us community-dwelling older adults. Med Care. 2017; 55(4): 371-8. Available from: https://doi. org/10.1097/MLR.0000000000000677

45. Joo H, Wang G, Yee SL, Zhang P, Sleet D. Economic Burden of Informal Caregiving Associated With History of Stroke and Falls Among Older Adults in the U.S. Am J Prev Med. 2017; 53(6): S197-204. Available from: https://doi.org/10.1016/j.amepre.2017.07.020

46. Li F, Zeng J, Huang J, Zhang J, Chen Y, Yan H, et al. Work-related and non-work-related accident fatal falls in Shanghai and Wuhan,
China. Saf Sci. 2019; 117: 43-8. Available from: https://doi.org/10.1016/j. ssci.2019.04.001

47. Center For Disease Control and Prevention. Make STEADI Part of Your Medical Practice | STEADI - Older Adult Fall Prevention | CDC Injury Center. [cited 2020 Mar 4]. Available from: https://www.cdc. gov/steadi/index.html

48. Karani M V, Haddad Y, Lee R. The role of pharmacists in preventing falls among America's older adults. Front Public Heal. 2016; 4: 250. Available from: https://doi.org/10.3389/fpubh.2016.00250

49. Johnston Y. A steadi initiative in primary care: evidence of reduction in falls-related hospitalizations. Innov Aging. 2018; 2(Suppl 1): 237.

50. Kruschke C, Butcher HK. Evidence-Based Practice Guideline: Fall Prevention for Older Adults. J Gerontol Nurs. 2017; 43(11): 15-21.

51. Coe LJ, St. John JA, Hariprasad S, Shankar KN, Mac Culloch PA, Bettano AL, et al. An integrated approach to falls prevention: A model for linking clinical and community interventions through the massachusetts prevention and wellness trust fund. Front Public Heal. 2017; 5: 38. Available from: https://doi.org/10.3389/fpubh.2017.00038

52. Ong ACW, Low SG, Vasanwala FF. Childhood injuries in Singapore: Can local physicians and the healthcare system do more to confront this public health concern? Int J Environ Res Public Health. 2016; 13(7): 718. Available from: https://doi.org/10.3390/ijerph13070718

53. Keall MD, Pierse N, Howden-Chapman P, Cunningham C, Cunningham $\mathrm{M}$, Guria J, et al. Home modifications to reduce injuries from falls in the Home Injury Prevention Intervention (HIPI) study: A clusterrandomised controlled trial. Lancet. 2015; 385(9964): 231-8. Available from: https://doi.org/10.1016/S0140-6736(14)61006-0

54. Hanger HC. Low-Impact Flooring: Does It Reduce Fall-Related Injuries? J Am Med Dir Assoc. 2017; 18(7): 588-91. Available from: https://doi. org/10.1016/j.jamda.2017.01.012

55. Carande-Kulis V, Stevens JA, Florence CS, Beattie BL, Arias I. A costbenefit analysis of three older adult fall prevention interventions. J Safety Res. 2015; 52: 65-70. Available from: https://doi.org/10.1016/j. jsr.2014.12.007

56. Thompson C, Holskey T, Wallenrod S, Simunovich S, Corn R. Effectiveness of a Fall Prevention Exercise Program on Falls Risk in Community-Dwelling Older Adults. Transl J Am Coll Sport Med. 2019; 4(3): 16. Available from: https://doi.org/10.1249/TJX.0000000000000078 57. Vlaeyen E, Coussement J, Leysens G, Van Der Elst E, Delbaere K, Cambier D, et al. Characteristics and effectiveness of fall prevention programs in nursing homes: A systematic review and meta-analysis of randomized controlled trials. J Am Geriatr Soc. 2015; 63(2): 211-21. Available from: https://doi.org/10.1111/jgs.13254

58. Olij B, Erasmus V, Barmentloo L, Burdorf A, Smilde D, Schoon Y, et al. Evaluation of Implementing a Home-Based Fall Prevention Program among Community-Dwelling Older Adults. Int J Environ Res Public Health. 2019; 16(6): 1079. Available from: https://doi.org/10.3390/ ijerph16061079

59. Lord SR, Close JCT. New horizons in falls prevention. Age Ageing. 2018; 47(4): 492-8. Available from: https://doi.org/10.1093/ageing/afy059

60. Arkkukangas M, Cederbom S, Tonkonogi M, Umb Carlsson Õ. Older adults' experiences with mHealth for fall prevention exercise: usability and promotion of behavior change strategies. Physiother Theory Pract. 2020; 1-7. Available from: https://doi.org/10.1080/09593985.2020.17 12753

61. Delbaere K, Valenzuela T, Woodbury A, Davies T, Yeong J, Steffens $\mathrm{D}$, et al. Evaluating the effectiveness of a home-based exercise programme delivered through a tablet computer for preventing falls in older community-dwelling people over 2 years: study protocol for the Standing Tall randomised controlled trial. BMJ Open. 2015; 5(10): e009173. Available from: https://doi.org/10.1136/bmjopen-2015-009173

62. Vieira ER, Palmer RC, Chaves PHM. Prevention of falls in older people living in the community. BMJ. 2016; 353: i1419. Available from: https:// doi.org/10.1136/bmj.i1419 